\title{
Determinants of the Cost-Effectiveness of Statins
}

\author{
ALAN MORRISON, PhD, and HELENE GLASSBERG, MD
}

\begin{abstract}
OBJECTIVE: To examine the cost-effectiveness of statins in relation to different measures of effectiveness, differences in efficacy among individual statins, and the risk of coronary heart disease. Efficacy is defined here as the magnitude of the effect produced by a given amount of drug, as demonstrated in placebocontrol trials; i.e., the effectiveness per unit dose.

DATA SYNTHESIS: Treatment guidelines categorize patients by their risk of coronary events and set lower target cholesterol levels for patients at higher risk. Statins vary in their efficacy. If effectiveness is expressed as percent lowering in low-density lipoprotein cholesterol (LDL-C) and relatively little cholesterol lowering is required-as in low-risk patients-even statins of low efficacy provide adequate cholesterol lowering, and drug price is the determining factor of costeffectiveness. For patients at high risk - the primary target group, which has been expanded in recent guidelines-high-efficacy statins are required to meet the more aggressive cholesterol goals, and efficacy is the important determinant of cost-effectiveness. When effectiveness is expressed in terms of life-years saved, the cost-effectiveness of statins as a class for treatment of high-risk patients compares favorably with the cost-effectiveness of generally accepted medical treatments.

CONCLUSION: In order to optimize cost-effectiveness, the level of effectiveness required to treat the specific patient or patient group must be considered. Statin efficacy is the major determinant of cost-effectiveness when greater cholesterol lowering is required, i.e., for high-risk patients, who make up the primary target group. Statin price is the more important factor if only limited cholesterol lowering (e.g., $35 \%$ or less reduction in LDL) is required.
\end{abstract}

KEYWORDS: Hydroxymethylglutaryl-CoA reductase inhibitors, Cost-effectiveness analysis, Drug therapy, Economics, Coronary disease

J Managed Care Pharm. 2003;9(6):544-51
$\mathrm{H}$ igh blood cholesterol is a major modifiable risk factor for coronary heart disease (CHD), the primary cause of illness-related death in the United States. ${ }^{1,2}$ Every $10 \%$ reduction in total cholesterol decreases the risk of coronary death by $15 \% .^{3}$ Hence, cholesterol-lowering treatments, including statins (inhibitors of hydroxymethylglutaryl-CoA reductase), have been recommended in national guidelines for an ever-widening section of the population.

The guidelines issued by the National Cholesterol Education Program (NCEP) Adult Treatment Panel (ATP) III placed patients in 3 risk categories: (1) those with established CHD and those with a 10-year risk of coronary events equivalent to that of CHD, (2) those with hypercholesterolemia and 2 or more risk factors, and (3) those with hypercholesterolemia and less than 2 risk factors. The guidelines set low-density lipoprotein cholesterol (LDL-C) treatment goals of $<100 \mathrm{mg} / \mathrm{dL}$, $<130 \mathrm{mg} / \mathrm{dL}$, and $<160 \mathrm{mg} / \mathrm{dL}$, respectively, for patients in these 3 groups (Table 1). ${ }^{4}$

These categories and LDL-C treatment goals are similar to those in the ATP II guidelines published in 1993 except that in the earlier guidelines, only patients with established CHD were included in the first risk category. ${ }^{5}$ The broadened indications for treatment in the ATP III guidelines increased the number of people in the United States who require cholesterol-lowering drugs to about 36 million, up from about 12.7 million in the ATP II guidelines. ${ }^{6}$

Outcomes studies have revealed a considerable gap between NCEP recommendations and clinical practice in the United States. ${ }^{7-9}$ Sixty-two percent of patients receiving lipid-lowering therapy in the L-TAP study, a study of 4,888 patients in 5 regions of the United States, did not meet their LDL-C goal. ${ }^{7}$ Similarly, in a retrospective study of 7,619 patients treated with statins at 27 managed care plans, 37\% did not reach their LDL-C goal. ${ }^{8}$ Consistently in these and other studies, the percent of patients achieving their ATP treatment goals was lowest in the highest-risk groups-i.e., those patients most in need of effective treatment..$^{7-10}$

Statins are established as first-line cholesterol-lowering drugs and are the pharmacologic treatment of choice because of their effectiveness and safety. ${ }^{10,11}$ The expanded indications for treatment in the ATP III guidelines and evidence of widespread undertreatment increase the need for statin therapy and will increase demand (Table 1). For managed care, this raises questions about the costs and cost-effectiveness of statins. In particular: What determines the cost-effectiveness of statins? Are there differences among the statins in cost-effectiveness? Are statins as a class "cost effective"? For which patients are statins most cost effective? In order to address these questions, we 
reviewed the statin pharmacoeconomic literature and examined the factors that determine the cost-effectiveness of statin treatment.

\section{Incremental Cost-Effectiveness}

The cost-effectiveness ratio usually referred to in pharmacoeconomics is the incremental cost-effectiveness ratio, which compares the costs and effects of one treatment (here, statins) with those of another (typically patients' usual care). The incremental costeffectiveness ratio is defined as the difference in the cost of the 2 treatments (statin and usual care) divided by the difference in their effectiveness:

$$
\text { Cost/Effectiveness }=\frac{\text { Cost (statin) }- \text { Cost (usual care) }}{\text { Effectiveness (statin) }- \text { Effectiveness (usual care) }}
$$

Alternative treatments typically vary both in their cost and in their effectiveness. The goal is to find the treatment with the least cost for the greatest effectiveness, i.e., the treatment with the smallest (most favorable) cost-effectiveness ratio. It is evident from the above equation that the cost-effectiveness ratio can be minimized by decreasing the cost or increasing the effectiveness. The equation does not, however, specify how costs and effectiveness are to be defined. The cost is expressed in currency, but effectiveness can be expressed in a number of ways. The measures of effectiveness we shall consider are the average percent reduction in LDL-C per patient, the proportion of patients reaching their LDL-C goal, and number of life-years saved (LYS). These different measures imply different time horizons and corresponding differences in the costs that must be considered.

\section{Differences Among Statins in Efficacy and Price}

Six statins-atorvastatin, fluvastatin, lovastatin, pravastatin, rosuvastatin, and simvastatin-are currently marketed in the United States. These statins vary considerably in price and efficacy. Efficacy is defined here as the magnitude of the effector effectiveness-produced by a given amount of drug. It can be understood as the inverse of potency, which is the amount of drug required to produce a given effect.

Table 2 lists prices and effectiveness, expressed as percent reduction in LDL-C, for different statin dosages. The effectiveness of statins increases with dosage, but efficacy is a fixed property for each statin. There are 2 ways of increasing the effectiveness: (a) increasing the dose of a given statin or (b) using the same dose of another statin with greater efficacy. There are limits, however, to the extent to which the effectiveness of statins with relatively low efficacy can be increased by raising the dose. As an example, the effectiveness of pravastatin $80 \mathrm{mg}$ (measured as percent reduction in LDL-C) is 65\% greater than that of pravastatin $10 \mathrm{mg}$ but still less than that of rosuvastatin $5 \mathrm{mg}$ and considerably less than that of higher dosages of statins with greater efficacy. Although it has been argued that the statins are clinically interchangeable, ${ }^{12}$ the differences in efficacy and price have important consequences in the determination of cost-

TABLE 1) LDL-C Goals and Cut Points for
Drug Therapy by Risk Category
in the NCEP III Guidelines*

ATP $=$ Adult Treatment Panel.

$\mathrm{CHD}=$ coronary heart disease

LDL-C = low-density lipoprotein cholesterol.

NCEP = National Cholesterol Education Program

* ATP III is based on the earlier ATP II and has the same LDL-C goals for the 3 risk categories. The highest risk category in ATP III includes patients with a risk of major coronary events equivalent to that of established CHD (in ATP II, only patients with established CHD were in the highest risk category). CHD risk equivalents include other forms of atherosclerotic disease, diabetes, and combinations of multiple risk factors conferring a 10-year risk of CHD of $>20 \%$. By focusing more on the 10-year risk of coronary events rather than simply on risk factors and placing more patient groups in the higher risk categories, ATP III expands the indications for intensive cholesterol-lowering therapy. ${ }^{4}$

+ Major risk factors (exclusive of LDL-C) that modify LDL-C goals include cigarette smoking, hypertension (blood pressure $\geq 140 / 90 \mathrm{~mm} \mathrm{Hg}$ or use of an antihypertensive medication), low HDL-C ( $<40 \mathrm{mg} / \mathrm{dL}$ ), family history of premature CHD, age (men $\geq 45$ years; women $\geq 55$ years). Diabetes is considered as a CHD risk equivalent.

\# Almost all people with 0-1 risk factors have a 10-year risk <10\%; 10-year risk assessment in these patients is not necessary.

effectiveness of statins, as demonstrated below.

\section{Relationship Between Efficacy and Cost-Effectiveness}

The relationship between the efficacy and cost-effectiveness of individual statins can be visualized in a scatter plot of the cost versus the effect. Figure 1 shows such a plot, where effectiveness is expressed as percent lowering of LDL-C and costs are expressed as annual drug costs, based on October 2003 prices from an online pharmacy. The line in Figure 1 describes the "efficient frontier," consisting of those points representing the lowest cost at any given level of effectiveness. Rosuvastatin and generic lovastatin lie on the efficient frontier at higher and lower levels, respectively, of effectiveness; fluvastatin $80 \mathrm{mg}$ and atorvastatin $10 \mathrm{mg}$ lie on the efficient frontier at intermediate levels of effectiveness. If, for example, the level of effectiveness is set at $45 \%$ reduction in LDL-C, rosuvastatin $10 \mathrm{mg}$ has the lowest cost; in the absence of rosuvastatin, atorvastatin $40 \mathrm{mg}$ would have the lowest cost at that level of effectiveness. At higher lev- 


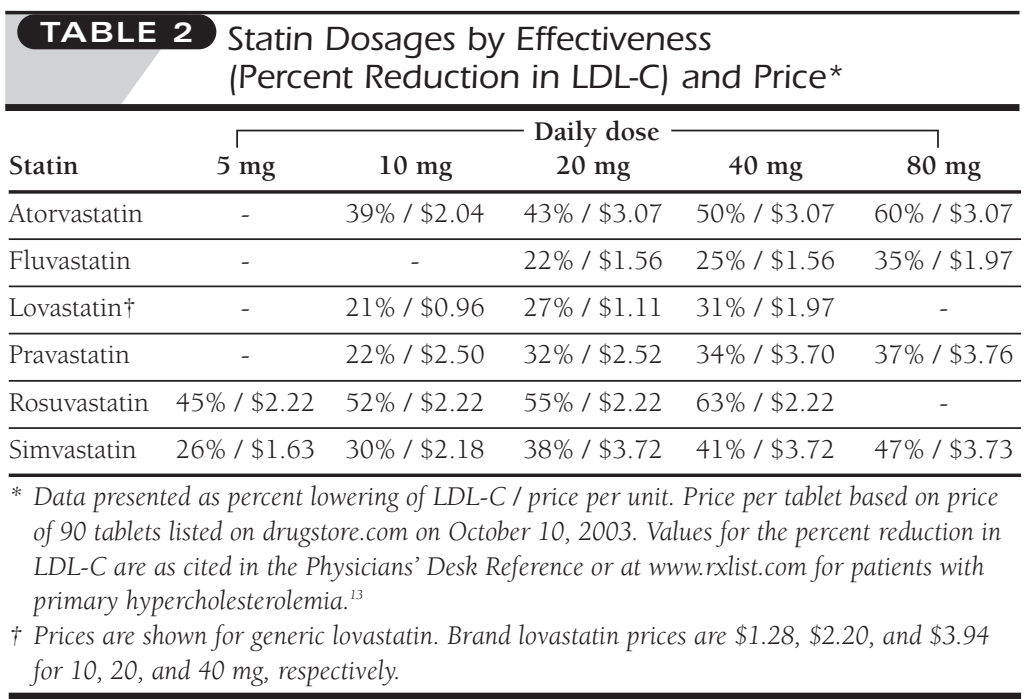

\section{FIGURE 1$)$ Annual Statin Cost by} Percent Reduction in LDL-C

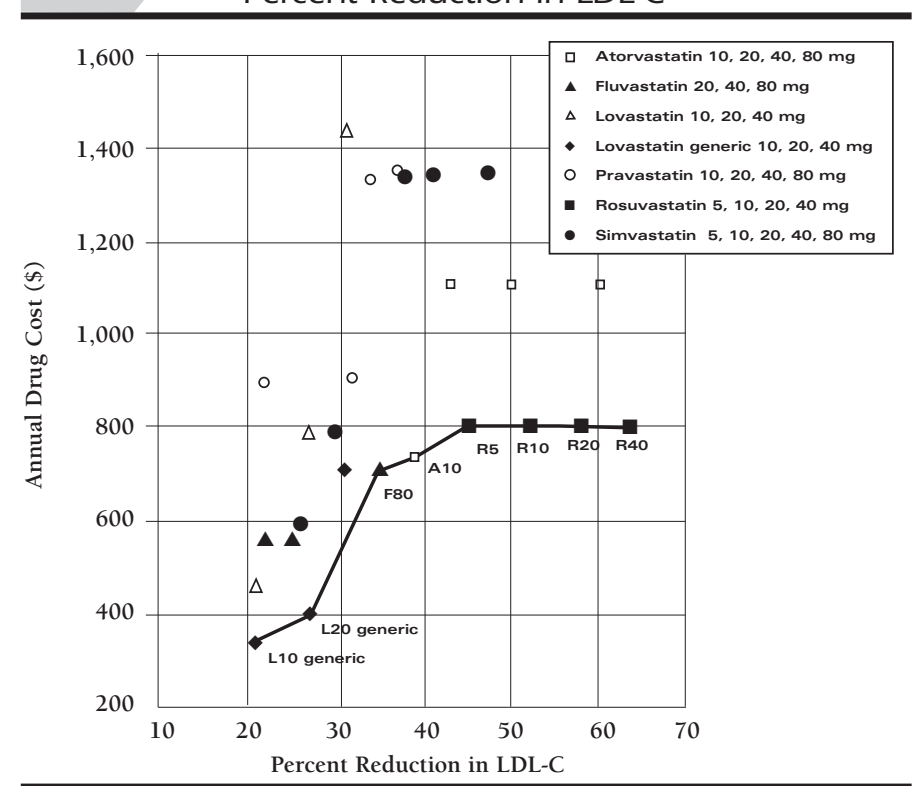

In this presentation of cost-effectiveness, drug acquisition costs are the only costs considered, and effectiveness is expressed as the percent reduction in LDL-C. The curve approximates the "efficient frontier," which tracks the lowest cost at any given level of effectiveness. Statin dosages that lie on the efficient frontier are labeled: L10, L20, and L40 generic, generic lovastatin $10 \mathrm{mg}, 20 \mathrm{mg}$, and $40 \mathrm{mg} ; \mathrm{R} 5, \mathrm{R} 10, \mathrm{R} 20$, and $\mathrm{R} 40$, rosuvastatin $5 \mathrm{mg}, 10 \mathrm{mg}, 20 \mathrm{mg}$, and $40 \mathrm{mg}$. Annual drug costs are based on prices for 90-pill packages, as listed on drugstore.com on October 10, 2003. Effectiveness data are from the Physician' Desk Reference or www.rxlist.com as indicated in the legend to Table $2 .^{13}$

els of effectiveness, the statin with the greatest efficacy (rosuvastatin) has the lowest cost-effectiveness ratio; i.e., is most cost effective. At low levels of effectiveness (e.g., less than 30\% reduction in LDL-C) the lowest-priced statin has the lowest cost-effectiveness ratio; i.e., is the most costeffective. The lowest-priced statin currently is generic lovastatin.

Essentially the same results have been obtained in several similar analyses set in the United States and Canada. ${ }^{14-16}$ The effectiveness data (average percent reduction in LDL-C per patient) for these analyses were gleaned from published sources, and the costs were annual drug costs, again expressed as average wholesale prices (AWPs) for the U.S. study ${ }^{14}$ or as average reimbursements for the 2 Canadian studies. ${ }^{15,16}$ In each of these studies, the efficient frontier was defined by the statin with the greatest efficacy then available-simvastatin in one study ${ }^{16}$ and atorvastatin in 2 later studies, ${ }^{14,15}$ and by the least expensive statin, then fluvastatin.

\section{NCEP ATP III Risk Groups}

When effectiveness is measured in terms of the proportion of patients reaching a target LDL-C threshold, effectiveness is dependent on patients' initial LDL-C level and on their target level. Since the LDL-C target levels recommended by the NCEP are lower for patients at higher risk of CHD, effectiveness (expressed as the percent of patients reaching their LDL-C goal) and, therefore, cost-effectiveness, are dependent on the risk of CHD. Figure 2 shows a scatter plot of annual statin cost versus percent of patients achieving their ATP III treatment goal for patients in the highest risk category (CHD and CHD-risk equivalents). The picture is similar to that in Figure 1 for the statins shown, which include the higher-efficacy statins (atorvastatin, rosuvastatin, and simvastatin) and pravastatin. Again, atorvastatin $10 \mathrm{mg}$ and rosuvastatin $5 \mathrm{mg}$, $10 \mathrm{mg}, 20 \mathrm{mg}$, and $40 \mathrm{mg}$ lie on the efficient frontier. The lower-efficacy statins, including pravastatin, are not effective in the high-risk patient group.

For patients in the lower ATP III risk groups, the data points and the efficient frontier seen in Figure 2 are shifted to the right. Table 3 shows the percent patients reaching their LDL-C goal for each of the 3 ATP III risk categories. For patients in the lowest risk group (fewer than 2 CHD risk factors), even low-efficacy statins such as pravastatin can bring most patients to their treatment goal (Table 3); under these circumstances, it is drug price rather than efficacy that is the more important determinant of cost-effectiveness.

Table 3 illustrates the concept that, as CHD risk decreases, statin efficacy is relatively less important. There are, however, some caveats to the interpretation of these results. First, the relationship between CHD risk and effectiveness seen in Figure 2 is a consequence of the method of expressing effectiveness and the fact that the NCEP target LDL-C levels are set lower for higher-risk groups. Second, it is generally not the case that all low-risk patients reach their LDL-C treatment goal. 
Outcomes studies have shown that many patients in the lowrisk category do not reach their LDL-C goal. ${ }^{7-10}$ The failure to reach LDL-C goal may be due, in part, to low adherence, ${ }^{17}$ but inadequate treatment, due to failure to titrate and low-efficacy therapies, also contributes to failure to reach LDL-C goal. ${ }^{7,9,10}$ Third, the use of the percent of patients reaching their LDL-C treatment goal as a measure of effectiveness ignores any potential benefit of reducing LDL-C levels to below recommended thresholds.

Preliminary data from the Heart Protection Study indicate that statin treatment reduces the risk of coronary events in some patient categories (those with a history of heart disease, stroke, other occlusive vascular disease, or diabetes) even when their cholesterol levels are normal. ${ }^{18}$ Furthermore, there appears to be no threshold cholesterol value below which statin therapy is not associated with a benefit, even among those with pretreatment cholesterol levels below current national recommended targets.

\section{Titration to LDL-C Treatment Goal}

The situation illustrated in Figures 1 and 2, in which patients continue with their initial statin dose, may, in fact, represent reality for many patients. Outcomes studies indicate that many patients-about half in some studies-do not receive LDL-C level monitoring or appropriate statin dose adjustment. ${ }^{8,9}$ In contrast, the NCEP guidelines recommend drug titration until patients reach their treatment goal (or the maximum dose) if the initial dose is inadequate. ${ }^{4}$ In this scenario, effectiveness is appropriately measured as the percent of patients reaching their LDL-C treatment goal.

The costs that must be considered are all those associated with measuring and remeasuring patients' cholesterol levels, including the costs of office visits and laboratory tests, as well as drug acquisition costs. This scenario was examined in a pharmacoeconomic analysis based on a 54-week, randomized, multicenter trial in the United States, in which starting doses of 4 statins were titrated upwards until patients with and without atherosclerosis reached the ATP II goal for LDL-C (or the maximum dose was reached). ${ }^{5,19}$ All related medical costs (drugs, office visits, laboratory tests) were considered from the perspective of insurers and managed care organizations and were based on national averages. ${ }^{19}$ The statin with the greatest efficacyatorvastatin, in that study-was "dominant," i.e., it was both more effective and less costly than dose titration with the other statins. Note, however, that once drug titration has been completed, the costs of long-term maintenance therapy are principally the direct drug-acquisition costs. ${ }^{20}$

\section{Cost per Life-Year Saved}

Since hypercholesterolemia is clinically silent, survival is the ultimate measure of statin effectiveness, not cholesterol lowering. When effectiveness is measured in terms of survival as the number of LYS, the costs that must be considered include not

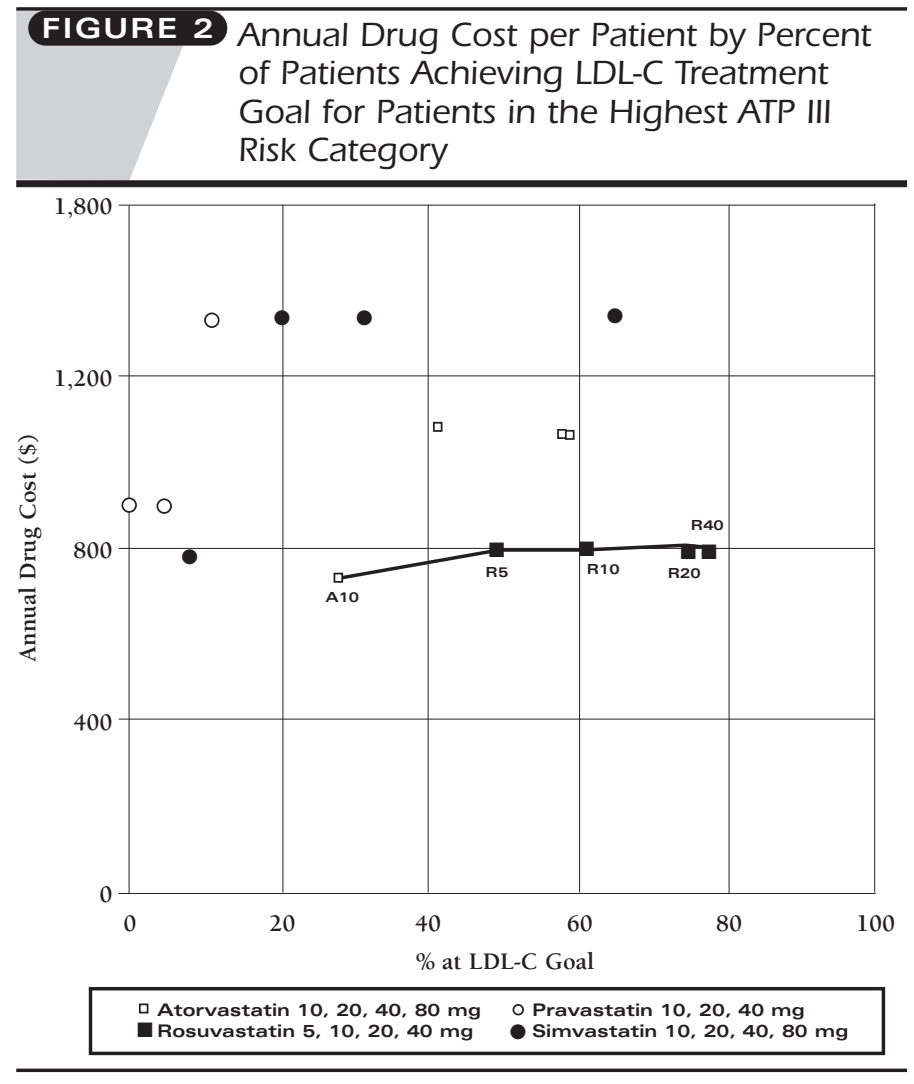

The highest ATP III risk category contains patients with CHD and CHD-risk equivalents. The line shows the efficient frontier, defined as in the caption to Figure 1. Statin dosages that lie on the efficient frontier are labeled: A10, atorvastatin $10 \mathrm{mg}$; $\mathrm{R} 5, \mathrm{R} 10, \mathrm{R} 20$, and R40, rosuvastatin $5 \mathrm{mg}, 10 \mathrm{mg}, 20 \mathrm{mg}$, and $40 \mathrm{mg}$. The source for drug costs is as in Figure 1. The sources of the effectiveness data are (except for rosuvastatin $5 \mathrm{mg}$ ) the STELLAR trial, ${ }^{41}$ and mean values from the comparative trials referenced as follows: rosuvastatin $5 \mathrm{mg},{ }^{43-46}$ rosuvastatin $10 \mathrm{mg},{ }^{41-45}$ atorvastatin $10 \mathrm{mg},{ }^{41,42,45}$ simvastatin $20 \mathrm{mg},{ }^{41,43,44}$ and pravastatin $20 \mathrm{mg}^{41,43,44}$

\section{TABLE 3 Percent of Patients Achieving LDL-C Treatment Goal by ATP III Risk Category for Selected Statin Dosages}

\begin{tabular}{lccc}
\hline & \multicolumn{2}{c}{ Percent of Patients at ATP III Treatment Goal* } \\
Statin Dosage & $\begin{array}{c}\text { CHD and CHD } \\
\text { Risk Equivalents }\end{array}$ & $\begin{array}{c}\text { 2 Risk } \\
\text { Factors }\end{array}$ & $\begin{array}{c}\text { 0-1 Risk } \\
\text { Factors }\end{array}$ \\
\hline Pravastatin 20 mg & 6 & 40 & 89 \\
Simvastatin 20 mg & 23 & 74 & 90 \\
Atorvastatin 10 mg & 25 & 79 & 92 \\
Rosuvastatin 10 mg & 62 & 89 & 98 \\
\hline
\end{tabular}

* ATP III risk categories as defined in Table 1. Effectiveness data are mean values from the comparative trials referenced as follows: rosuvastatin $10 \mathrm{mg}$, ${ }^{41-45}$ atorvastatin $10 \mathrm{mg}^{41,42,45}$ simvastatin $20 \mathrm{mg},{ }^{41,43,44}$ and pravastatin $20 \mathrm{mg}^{41,43,44}$

just statin therapy and dose titration but also medical treatments for CHD (which are reduced for patients treated with statins). More than 30 pharmacoeconomic analyses of the cost 


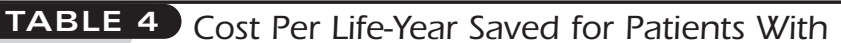 and Without Preexisting Coronary Heart Disease in the United States}

\begin{tabular}{|c|c|c|}
\hline Study & Statin & Cost per LYS $(\$ 1,000 s)^{* \dagger}$ \\
\hline \multicolumn{3}{|l|}{ With Preexisting CHD } \\
\hline Ashraf, et al. $(1996)^{36}$ & Pravastatin & $7.1-12.7$ \\
\hline Elliott $1999^{37,38} \neq$ & Various & $2.3-30.9$ \\
\hline Ganz $2000^{39} \ddagger 8$ & Pravastatin & $5.4-97.8$ \\
\hline Goldman $1991^{27}$ & Lovastatin & $<0-310$ \\
\hline Grover $1999^{40}$ & Simvastatin & $4.4-21.7$ \\
\hline Huse $1998^{29}$ & Various & $8.2-63.6$ \\
\hline Johannesson $1997^{41}$ & Simvastatin & $3.8-27.4$ \\
\hline Prosser $2000^{26}$ & Simvastatin & $1.8-40.0$ \\
\hline \multicolumn{3}{|c|}{ Without Preexisting CHD } \\
\hline Goldman $1991^{27}$ & Lovastatin & $13.0-1,500$ \\
\hline Hay $1991^{28}$ & Lovastatin & $6.0-297$ \\
\hline Huse $1998^{29}$ & Various & $4.3-468$ \\
\hline Prosser $2000^{26} \dagger$ & Pravastatin & $54.0-1,400$ \\
\hline \multicolumn{3}{|c|}{$\begin{array}{l}\text { LYS }=\text { life-years saved. } \\
* \text { Range of values (lower and upper) for the highest-and lowest-risk patient groups, } \\
\text { respectively (except where indicated). } \\
+ \text { Costs are unadjusted for inflation and are expressed in } \$ U . S . \text { for } 1989,{ }^{27,28} \\
1995,{ }^{35,40} 1996,{ }^{39} 1997,26,29 \\
1998,,^{38} \text { and } 1999 .{ }^{36} \\
\text { † The lower and upper limits represent the most favorable and least favorable model } \\
\text { scenarios rather than patient risk groups. } \\
\text { \& Cost per quality-adjusted life-year reported. }\end{array}$} \\
\hline
\end{tabular}

TABLE 5 The Cost Per Life-Years Saved of Statin Treatment Decreases as the Risk Factors for Events Increase*

\begin{tabular}{|c|c|c|c|c|c|c|}
\hline \multirow{2}{*}{$\frac{\mathrm{LDL}-\mathrm{C}(\mathrm{mg} / \mathrm{dL})}{}$} & \multirow[b]{2}{*}{ Sex } & \multicolumn{2}{|c|}{ Risk Factors } & \multirow[b]{2}{*}{ Smoker } & \multirow[b]{2}{*}{ CHD } & \multirow[t]{2}{*}{$\begin{array}{c}\text { Cost- } \\
\text { Effectiveness } \\
(\$ / \text { LYS })\end{array}$} \\
\hline & & HTN & Obese & & & \\
\hline$\geq 300$ & $\mathrm{~F}$ & - & - & - & - & 130,000 \\
\hline 250-299 & $\mathrm{M}$ & - & - & - & - & 93,000 \\
\hline$\geq 300$ & $\mathrm{M}$ & - & - & - & - & 58,000 \\
\hline$\geq 300$ & M & + & - & - & - & 28,000 \\
\hline$\geq 300$ & $\mathrm{M}$ & + & + & - & - & 17,000 \\
\hline$\geq 300$ & $\mathrm{M}$ & + & + & + & - & 15,000 \\
\hline$<250$ & $\mathrm{M}$ & & & & + & 17,000 \\
\hline$\geq 250$ & $\mathrm{~F}$ & & & & + & 8,100 \\
\hline$\geq 250$ & $\mathrm{M}$ & & & & + & 1,600 \\
\hline
\end{tabular}

$\mathrm{CHD}=$ coronary heart disease.

HTN = hypertension

LYS = life-years saved.

* Data of Goldman et al. for people 55 to 64 years of age treated with lovastatin $20 \mathrm{mg} .{ }^{27}$ Definitions: hypertensive, diastolic blood pressure $\geq 105 \mathrm{~mm} \mathrm{Hg}$; normotensive, diastolic blood pressure $<95 \mathrm{~mm} \mathrm{Hg}$; obese, $\geq 130 \%$ of ideal weight; nonobese, $<110 \%$ of ideal weight.

of statins per LYS have been reported. In these analyses, the data for the incidence of $\mathrm{CHD}$, risk factors, and coronary events in patient-lifetime projections typically comes from the Framingham Heart Study, while the data for the effects of statins on coronary events comes from long-term clinical event trials with lovastatin, pravastatin, and simvastatin: the WOSCOPS (West of Scotland Coronary Prevention Study) $)^{21}$ and AFCAPS/TexCAPS (Air Force/Texas Coronary Atherosclerosis Prevention Study) ${ }^{22}$ primary prevention trials and the $4 S$ (Scandinavian Simvastatin Survival Study), ${ }^{23}$ CARE (Cholesterol and Recurrent Events), ${ }^{24}$ and LIPID (Long-Term Intervention with Pravastatin in Ischaemic Disease ${ }^{25}$ secondary prevention trials. In some analyses, the cost per quality-adjusted life-year (QALY) was determined; this adjustment for quality of life increases cost-effectiveness ratios by about $10 \%$ to $20 \% .{ }^{26}$

In most analyses of patients with preexisting $\mathrm{CHD},{ }^{26-29}$ the ranges of lifetime incremental cost per LYS values lie in the range of $\$ 1,800$ to $\$ 40,000$ (Table 4 ). The upper limits of the ranges exceed $\$ 50,000$ in some studies, but only for patients in the lowest risk groups. ${ }^{27,29}$ For subjects without preexisting $\mathrm{CHD}$, the lifetime cost-effectiveness ratios vary over an extremely wide range-more than 100 -fold in some studies ${ }^{27,29}$ - from lower limits generally below $\$ 15,000$ to upper limits sometimes exceeding $\$ 1$ million per LYS (Table 4). ${ }^{26,27}$ The critical factor is the risk of CHD: the cost-effectiveness ratio tends to decrease as the risk of coronary events increases. This is illustrated in Table 5, which shows data of Goldman et al. ${ }^{27}$ This relationship holds because the effectiveness measure-LYS—depends on the number of coronary events avoided, which is greater in a highrisk population.

The cost of statins per LYS for patients with preexisting $\mathrm{CHD}$, and for those without $\mathrm{CHD}$ but with multiple risk factors, falls inside the threshold for an acceptable cost-effective ratio: the value of this threshold was about U.S. \$30,000 in the early 1990 s and $\$ 40,000$ to $\$ 50,000$ more recently. The cost-effectiveness values for statins also generally fall within the range of values for other currently accepted treatments: $\$ 7,700$ to $\$ 10,000$ for single-vessel angioplasty in patients with severe angina; $\$ 18,000$ for annual screening for colorectal cancer with a fecal occult blood test; $\$ 108,000$ to $\$ 112,000$ for single-vessel angioplasty in patients with mild angina; $\$ 15,000$ to $\$ 96,500$ for treatment of hypertension in patients aged 35 to 64 years; and $\$ 150,000$ for annual mammography in women aged 55 to 65 years (cost-effectiveness ratios expressed as 1995 U.S.\$ per QALY). ${ }^{26,30}$

\section{Specific Risk Groups}

In addition to patients with CHD, several at-risk patient groups have been subjected to cost-effectiveness analysis. Statin treatment of heterozygous familial hypercholesterolemia, which affects approximately 0.5 million people in the United States, is cost-saving for men and costs only $\$ 300$ per LYS for women, even without additional risk factors. ${ }^{31}$ Patients with type-2 diabetes have a risk of coronary events comparable to that of nondiabetic patients with a history of myocardial infarction. ${ }^{32}$ This suggests that the cost-effectiveness of statin treatment of these 
2 populations should be equivalent; this has not, however, been demonstrated in the primary prevention cost-effectiveness literature, where diabetes has been treated as a risk factor for CHD comparable to smoking or hypertension. ${ }^{29}$ Secondary prevention of coronary events in diabetic patients was studied in post hoc analyses of patient subgroups of the $4 S$ trial: ${ }^{33,34}$ The cost per LYS of simvastatin treatment was substantially lower for diabetic than for nondiabetic patients with CHD. ${ }^{33}$

\section{Statin Pricing}

In Figures 1 and 2, we presented cost-effectiveness data using current statin prices from an online pharmacy. We note that there have been changes in pricing policy by drug manufacturers over the past several years, such as a switch for some statins from higher prices for higher doses to flat pricing, as well as the introduction of new statins. Rosuvastatin has displaced atorvastatin at the upper end of the efficient frontier seen in Figure 1, just as atorvastatin previously displaced simvastatin. Lovastatin, which was the first statin to be marketed in the United States (in 1987), became available as a generic drug in 2002. Generic lovastatin has replaced fluvastatin at the lower end of the efficient frontier shown in Figure 1. However, generic lovastatin $40 \mathrm{mg}$ is comparable in effectiveness to simvastatin $10 \mathrm{mg}$ or pravastatin $20 \mathrm{mg}$, which bring less than $20 \%$ of highrisk patients to their LDL-C goal (Figure 2), so that generic lovastatin can only compete (on the basis of price) at lower levels of effectiveness. Outcomes studies indicate that the majority of patients currently being treated with statins are in the CHD or risk-equivalent category.-9

\section{Limitations}

Managed care organizations typically contract for statin prices at discounts to the AWP. Discount prices for the statin drugs were obtained from an online pharmacy Web site to help account for the difference in AWP prices and the actual costs incurred by managed care organizations (MCOs), prior to member cost share. However, actual statin purchase costs will differ among MCOs, and this may change the cost-effectiveness rankings of statins at any given level of effectiveness. Nevertheless, in order to optimize cost-effectiveness, MCOs must consider the level of effectiveness that is required to treat individual patients or specific patient groups rather than simply the lowest purchase price.

\section{Summary}

In principle, the incremental cost-effectiveness ratio can be reduced by decreasing the cost or by increasing the effectiveness of the therapy. Both of these effects are evident in the comparisons of individual statins. When effectiveness is expressed as percent reduction in LDL-C and cost as statin price, increasing the efficacy (the effect per unit dose) decreases the cost-effectiveness ratio and, when greater LDL-C lowering is required (as is the case with patients with CHD or CHD-equivalent risk), the statins with the greatest efficacy have the lowest (most favorable) cost-effectiveness ratios. If limited LDL-C lowering is required (as may be the case for some low-risk patients), drug price may be the more important factor.

The same relationships between the cost-effectiveness ratio and statin efficacy and price are also seen when effectiveness is expressed as the proportion of patients reaching LDL-C goal. The inverse relationship between statin efficacy and the costeffectiveness ratio holds up under the circumstances of statin titration to treatment goal and the inclusion of all related treatment costs. When effectiveness is expressed in terms of LYS and all long-term medical costs are taken into account, the incremental cost-effectiveness ratio decreases as the risk of CHD increases. For patients with preexisting CHD or CHD-equivalent risk of coronary events, the cost-effectiveness ratio of statins as a class compares favorably with generally accepted medical treatments.

The results suggest 3 strategies for minimizing the cost-effectiveness ratio of statin therapy. First, preferentially treat patients with existing CHD or equivalent risk; second, use statins with the greatest efficacy for these patients and for patients at low risk but with high baseline LDL-C levels; and third, use a less-expensive statin when less LDL-C lowering is needed, as in low-risk patients with lower baseline LDL-C levels.

\section{DISCLOSURES}

Funding for this study was provided by AstraZeneca LP and was obtained by author Alan Morrison. Morrison served as principal author of the study. Study concept and design and analysis and interpretation of data were contributed by Morrison. Drafting of the manuscript was the work of Morrison, and its critical revision was the work of Morrison and author Helene Glassberg.

\section{REFERENCES}

1. Hunink MG, Goldman L, Tosteson AN, et al. The recent decline in mortality from coronary heart disease, 1980-1990. The effect of secular trends in risk factors and treatment. JAMA. 1997;277(7):535-42

2. McGovern PG, Pankow JS, Shahar E, et al. Recent trends in acute coronary heart disease-mortality, morbidity, medical care, and risk factors. The Minnesota Heart Survey Investigators. N Engl J Med. 1996;334(14):884-90.

3. Gould AL, Rossouw JE, Santanello NC, Heyse JF, Furberg CD. Cholesterol reduction yields clinical benefit: impact of statin trials. Circulation. 1998;97 (10):946-52

4. Executive Summary of the Third Report of the National Cholesterol Education Program (NCEP) Expert Panel on Detection, Evaluation, and Treatment of High Blood Cholesterol in Adults (Adult Treatment Panel III). JAMA. 2001;285(19):2486-97.

5. Summary of the second report of the National Cholesterol Education Program (NCEP) Expert Panel on Detection, Evaluation, and Treatment of High Blood Cholesterol in Adults (Adult Treatment Panel II). JAMA. 1993; 269(23):3015-23

6. Sempos CT, Cleeman JI, Carroll MD, et al. Prevalence of high blood cholesterol among US adults. An update based on guidelines from the second report of the National Cholesterol Education Program Adult Treatment Panel. JAMA. 1993;269(23):3009-14 
7. Pearson TA, Laurora I, Chu H, Kafonek S. The lipid treatment assessment project (L-TAP): a multicenter survey to evaluate the percentages of dyslipidemic patients receiving lipid-lowering therapy and achieving low-density lipoprotein cholesterol goals. Arch Intern Med. 2000;160(4):459-67.

8. Latts LM. Assessing the results: phase 1 hyperlipidemia outcomes in 27 health plans. Am J Med. 2001;110(suppl 6A):17S-23S.

9. Marcelino JJ, Feingold KR. Inadequate treatment with HMG-CoA reductase inhibitors by health care providers. Am J Med. 1996;100(6):605-10.

10. Schectman G, Hiatt J. Drug therapy for hypercholesterolemia in patients with cardiovascular disease: factors limiting achievement of lipid goals. Am J Med. 1996;100(2):197-204.

11. Ansell BJ, Watson KE, Fogelman AM. An evidence-based assessment of the NCEP Adult Treatment Panel II guidelines. National Cholesterol Education Program. JAMA. 1999;282(21):2051-57.

12. Pedersen T, Gaw A. Statins-similarities and differences. Am J Managed Care. 2001;7(suppl 5):S132-S137.

13. Physicians' Desk Reference. 57th ed. Montvale, NJ: Thomson PDR; 2003.

14. Hilleman DE, Phillips JO, Mohiuddin SM, Ryschon KL, Pedersen CA. A population-based treat-to-target pharmacoeconomic analysis of HMG-CoA reductase inhibitors in hypercholesterolemia. Clin Ther. 1999;21(3):536-62.

15. Morris S, Godber E. Choice of cost-effectiveness measure in the economic evaluation of cholesterol-modifying pharmacotherapy. An illustrative example focusing on the primary prevention of coronary heart disease in Canada. Pharmacoeconomics. 1999;16(2):193-205.

16. Martens LL, Guibert R. Cost-effectiveness analysis of lipid-modifying therapy in Canada: comparison of HMG-CoA reductase inhibitors in the primary prevention of coronary heart disease. Clin Ther. 1994;16(6):1052-62. Discussion 1036.

17. Benner JS, Glynn RJ, Mogun H, Neumann PJ, Weinstein MC, Avorn J. Long-term persistence in use of statin therapy in elderly patients. JAMA. 2002;288(4):455-61.

18. MRC/BHF Heart Protection Study of cholesterol lowering with simvastatin in 20,536 high-risk individuals: a randomised placebo-controlled trial. Lancet. 2002;360(9326):7-22.

19. Koren MJ, Smith DG, Hunninghake DB, et al. The cost of reaching National Cholesterol Education Program (NCEP) goals in hypercholesterolaemic patients. A comparison of atorvastatin, simvastatin, lovastatin and fluvastatin. Pharmacoeconomics. 1998;14(1):59-70.

20. Attanasio E, Russo P, Allen SE. Cost-minimization analysis of simvastatin versus atorvastatin for maintenance therapy in patients with coronary or peripheral vascular disease. Clin Ther. 2001;23(2):276-83. Discussion 274-5.

21. Shepherd J, Cobbe SM, Ford I, et al. Prevention of coronary heart disease with pravastatin in men with hypercholesterolemia. West of Scotland Coronary Prevention Study Group. N Engl J Med. 1995;333(20):1301-07.

22. Downs JR, Clearfield M, Weis S, et al. Primary prevention of acute coronary events with lovastatin in men and women with average cholesterol levels: results of AFCAPS/TexCAPS. Air Force/Texas Coronary Atherosclerosis Prevention Study. JAMA. 1998;279(20):1615-22.

23. Randomised trial of cholesterol lowering in 4,444 patients with coronary heart disease: the Scandinavian Simvastatin Survival Study (4S). Lancet. 1994;344(8934): 1383-89.

24. Sacks FM, Pfeffer MA, Moye LA, et al. The effect of pravastatin on coronary events after myocardial infarction in patients with average cholesterol levels. Cholesterol and Recurrent Events Trial investigators. N Engl J Med. 1996;335(14):1001-09.

25. Glasziou PP, Simes RJ, Hall J, Donaldson C. Design of a cost-effectiveness study within a randomized trial: the LIPID Trial for Secondary Prevention of IHD. Long-term Intervention with Pravastatin in Ischemic Heart disease. Control Clin Trials. 1997;18(5):464-76.
26. Prosser LA, Stinnett AA, Goldman PA, et al. Cost-effectiveness of cholesterol-lowering therapies according to selected patient characteristics. Ann Intern Med. 2000;132(10):769-79.

27. Goldman L, Weinstein MC, Goldman PA, Williams LW. Cost-effectiveness of HMG-CoA reductase inhibition for primary and secondary prevention of coronary heart disease. JAMA. 1991;265(9):1145-51.

28. Hay JW, Wittels EH, Gotto AM Jr. An economic evaluation of lovastatin for cholesterol lowering and coronary artery disease reduction. Am J Cardiol. 1991;67(9):789-96.

29. Huse DM, Russell MW, Miller JD, et al. Cost-effectiveness of statins. Am J Cardiol. 1998;82(11):1357-63.

30. Graham JD, Corso PS, Morris JM, Segui-Gomez M, Weinstein MC. Evaluating the cost-effectiveness of clinical and public health measures. Annu Rev Public Health. 1998;19:125-52.

31. Goldman L, Goldman PA, Williams LW, Weinstein MC. Cost-effectiveness considerations in the treatment of heterozygous familial hypercholesterolemia with medications. Am J Cardiol. 1993;72(10):75D-79D.

32. Haffner SM, Lehto S, Ronnemaa T, Pyorala K, Laakso M. Mortality from coronary heart disease in subjects with type 2 diabetes and in nondiabetic subjects with and without prior myocardial infarction. N Engl J Med. 1998;339(4):229-34.

33. Jonsson B, Cook JR, Pedersen TR. The cost-effectiveness of lipid lowering in patients with diabetes: results from the 4S trial. Diabetologia. 1999;42(11): 1293-301.

34. Herman WH, Alexander CM, Cook JR, et al. Effect of simvastatin treatment on cardiovascular resource utilization in impaired fasting glucose and diabetes. Findings from the Scandinavian Simvastatin Survival Study. Diabetes Care. 1999;22(11):1771-78.

35. Ashraf T, Hay JW, Pitt B, et al. Cost-effectiveness of pravastatin in secondary prevention of coronary artery disease. Am J Cardiol. 1996;78(4):409-14.

36. Elliott WJ, Weir DR. Comparative cost-effectiveness of HMG-CoA reductase inhibitors in secondary prevention of acute myocardial infarction. Am J Health-Syst Pharm. 1999;56(17):1726-32.

37. Elliott WJ, Weir DR. Cost of cerivastatin in cost-effectiveness study. Am J Health-Syst Pharm. 2000;57(18):1713.

38. Ganz DA, Kuntz KM, Jacobson GA, Avorn J. Cost-effectiveness of 3-hydroxy-3-methylglutaryl coenzyme A reductase inhibitor therapy in older patients with myocardial infarction. Ann Intern Med. 2000;132(10):780-87.

39. Grover SA, Coupal L, Paquet S, Zowall H. Cost-effectiveness of 3-hydroxy3-methylglutaryl-coenzyme A reductase inhibitors in the secondary prevention of cardiovascular disease: forecasting the incremental benefits of preventing coronary and cerebrovascular events. Arch Intern Med. 1999;159(6):593-600.

40. Johannesson M, Jonsson B, Kjekshus J, Olsson AG, Pedersen TR, Wedel $\mathrm{H}$. Cost-effectiveness of simvastatin treatment to lower cholesterol levels in patients with coronary heart disease. Scandinavian Simvastatin Survival Study Group. N Engl J Med. 1997;336(5):332-36.

41. McKenney JM, Jones PH, Adamczyk MA, et al. Comparison of the efficacy of rosuvastatin versus atorvastatin, simvastatin and pravastatin in achieving lipid goals (results from the STELLAR trial). Curr Med Res Opin. 2003. In press.

42. Davidson M, Ma P, Stein EA, et al. Comparison of effects on low-density lipoprotein cholesterol and high-density lipoprotein cholesterol with rosuvastatin versus atorvastatin in patients with type IIa or IIb hypercholesterolemia. Am J Cardiol. 2002;89(3):268-75.

43. Paoletti R, Fahmy M, Mahla G, Mizan J, Southworth H. Rosuvastatin demonstrates greater reduction of low-density lipoprotein cholesterol compared with pravastatin and simvastatin in hypercholesterolaemic patients: a randomized, double-blind study. J Cardiovasc Risk. 2001;8(6):383-90. 
44. Brown WV, Bays HE, Hassman DR, et al. Efficacy and safety of rosuvastatin compared with pravastatin and simvastatin in patients with hypercholesterolemia: a randomized, double-blind, 52-week trial. Am Heart J. 2002; 144(6):1036-43.

45. Olsson AG, Istad H, Luurila O, et al. Effects of rosuvastatin and atorvastatin compared over 52 weeks of treatment in patients with hypercholesterolemia. Am Heart J. 2002;144(6):1044-51. 